\title{
Cognitive dysfunction in NFI knock-out mice may result from altered vesicular trafficking of APP/DRD3 complex Elizabeth A Donarum ${ }^{1}$, Rebecca F Halperin², Dietrich A Stephan ${ }^{2}$ and Vinodh Narayanan*1
}

Address: ${ }^{1}$ Developmental Neurogenetics Laboratory, Barrow Neurological Institute, St Joseph's Hospital and Medical Center, Phoenix AZ, 85013, USA and ${ }^{2}$ Neurogenomics Division, Translational Genomics Research Institute, Phoenix AZ, 85004, USA

Email: Elizabeth A Donarum - edonarum@aol.com; Rebecca F Halperin - rhalperin@tgen.org; Dietrich A Stephan - dstephan@tgen.org;

Vinodh Narayanan* - Vinodh.Narayanan@CHW.EDU

* Corresponding author

Published: 08 March 2006

BMC Neuroscience2006, 7:22 doi:10.1/86/147|-2202-7-22
Received: 03 November 2005

Accepted: 08 March 2006

This article is available from: http://www.biomedcentral.com/I47/-2202/7/22

(c) 2006Donarum et al; licensee BioMed Central Ltd.

This is an Open Access article distributed under the terms of the Creative Commons Attribution License (http://creativecommons.org/licenses/by/2.0), which permits unrestricted use, distribution, and reproduction in any medium, provided the original work is properly cited.

\begin{abstract}
Background: It has been estimated that more than $50 \%$ of patients with Neurofibromatosis type I (NFI) have neurobehavioral impairments which include attention deficit/hyperactivity disorder, visual/spatial learning disabilities, and a myriad of other cognitive developmental problems. The biological mechanisms by which NFI gene mutations lead to such cognitive deficits are not well understood, although excessive Ras signaling and increased GABA mediated inhibition have been implicated. It is proposed that the cognitive deficits in NFI are the result of dysfunctional cellular trafficking and localization of molecules downstream of the primary gene defect.
\end{abstract}

Results: To elucidate genes involved in the pathogenic process, gene expression analysis was performed comparing the expression profiles in various brain regions for control and $\mathrm{Nfl}^{+1-}$ heterozygous mice. Gene expression analysis was performed for hippocampal samples dissected from postnatal day 10, 15, and 20 mice utilizing the Affymetrix Mouse Genome chip (Murine 430 2.0). Analysis of expression profiles between $\mathrm{NfI}^{+/}$-and wild-type animals was focused on the hippocampus because of previous studies demonstrating alterations in hippocampal LTP in the $\mathrm{Nf}^{+/-}$mice, and the region's importance in visual/spatial learning. Network analysis identified links between neurofibromin and kinesin genes, which were down regulated in the $\mathrm{NF}{ }^{+/}$mice at postnatal days 15 and 20.

Conclusion: Through this analysis, it is proposed that neurofibromin forms a binding complex with amyloid precursor protein (APP) and through filamin proteins interacts with a dopamine receptor (Drd3). Though the effects of these interactions are not yet known, this information may provide novel ideas about the pathogenesis of cognitive defects in NFI and may facilitate the development of novel targeted therapeutic interventions.

\section{Background}

Neurofibromatosis type 1 (also known as von Recklinghausen disease) is an autosomal dominant disorder with a prevalence of 1 in 3500, and is characterized by hyperpigmented skin macules (café au lait spots), iris tumors (Lisch nodules), and benign tumors of nerve cells (neu- 
rofibromas) [1]. Other physical complications observed in NF1 patients include optic pathway gliomas, scoliosis, macrocephaly, epilepsy, chronic headaches, bending of the long bones (pseudoarthrosis), and sphenoid wing dysplasia [2]. Cognitive deficits in spatial learning and memory also accompany these more physical manifestations of NF1 [3]. Though mental retardation is not commonly seen in NF1 patients, a high proportion of children

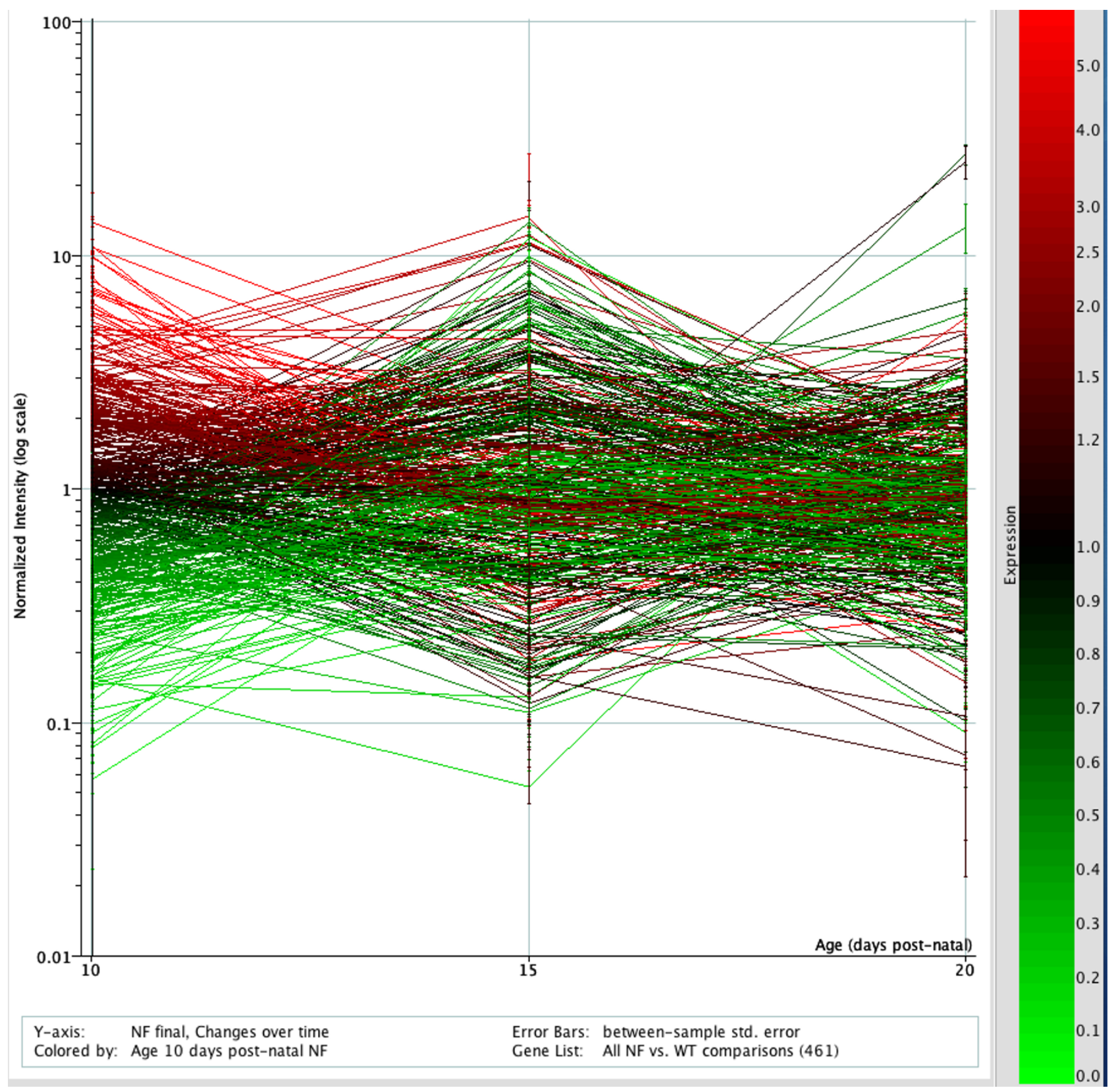

Figure I

Visualization of all expression fluctuations in the hippocampus across the time series. Visualization of genes in the second dataset showing a significant $(\mathrm{p} \leq 0.05)$ fold change of $\geq 2$ between $\mathrm{Nfl}^{+/}$- and wild type mice at one or more time points $(n=163)$. Genes showing increased expression in the mutant model appear in the red portion of the expression color spectrum with decreasing genes in the green portion. The normalized intensity is plotted on a log scale versus the postnatal age. Each line represents the expression of an individual gene. 
Table I: Genes at post natal day 10 showing fold change values of $\geq 2$ between $\mathrm{NfI}^{+/-}$and wild type mice $(\mathrm{p} \leq 0.05)$.

\begin{tabular}{|c|c|c|c|c|c|}
\hline Probe Set & Unigene & Fold Change & $P$ Value & Gene Name & Gene Symbol \\
\hline |42|984_at & Mm.209II & 12.2 & 0.00205 & stanniocalcin I & Stcl \\
\hline 1422207_at & Mm.4835 & 9.391 & 0.000624 & 5-hydroxytryptamine (serotonin) receptor $5 \mathrm{~A}$ & Htr5a \\
\hline$|426| 4 \mid$ at & Mm.207059 & 7.518 & 0.0351 & RF-amide G protein-coupled receptor & MrgAl \\
\hline |445983_at & Mm. 172835 & 6.707 & 0.0139 & ubiquitin-conjugating enzyme E2A, RAD6 homolog & Ube2a \\
\hline |4366|5_a_at & Mm.26II & 6.396 & 0.0416 & ornithine transcarbamylase & Otc \\
\hline |4577|3_at & $M m .2213$ & 6.388 & 0.0281 & excision repair cross-complementing rodent repair deficiency & Ercc5 \\
\hline 1459730_at & Mm.52297 & 5.653 & 0.0329 & formin binding protein I & Fnbpl \\
\hline |4463|5_at & Mm.282039 & 5.376 & 0.0362 & ATP citrate lyase & Acly \\
\hline 1430486_at & Mm.34I756 & 4.883 & 0.0493 & RAD5I-like I (S. cerevisiae) & Rad5III \\
\hline 1425443_at & Mm.244858 & 4.441 & 0.0239 & transcription factor AP-2, delta & Tcfap2d \\
\hline |45243|_s_at & Mm.235338 & 4.175 & 0.0242 & histocompatibility 2 , class II antigen A, alpha & $\mathrm{H} 2-\mathrm{Aa}$ \\
\hline 1433133_at & Mm.15967I & 3.708 & 0.0269 & EDAR (ectodysplasin-A receptor)-associated death domain & Edaradd \\
\hline 1429566_a_at & Mm.23790 & 3.69 & 0.0369 & homeodomain interacting protein kinase 2 & Hipk2 \\
\hline |426005_at & Mm.199008 & 3.673 & 0.00896 & dentin matrix protein I & Dmpl \\
\hline 1429668_at & Mm.246550 & 3.67 & 0.0389 & POU domain, class 4 , transcription factor I & Pou4fI \\
\hline |4|586I_at & Mm.30438 & 3.651 & 0.0382 & tyrosinase-related protein I & Tyrpl \\
\hline |4273|3_at & Mm.287572 & 3.557 & 0.0125 & prostaglandin I receptor (IP) & Ptgir \\
\hline |435663_at & Mm.9213 & 3.449 & 0.00753 & estrogen receptor I (alpha) & Esrl \\
\hline |44|957_x_at & Mm.205196 & 3.211 & 0.0202 & stromal cell derived factor receptor I & Sdfr I \\
\hline 1422038_a_at & Mm.261384 & 3.19 & 0.0384 & tumor necrosis factor receptor superfamily, member 22 & Tnfrsf22 \\
\hline |421967_at & Mm.200886 & 3.031 & 0.0318 & UDP-Gal:betaGIcNAc beta I,4-galactosyltransferase, polypeptide 5 & B4galt5 \\
\hline 1419085_at & Mm.4I456 & 2.949 & 0.0459 & Purkinje cell protein 2 (L7) & Pcp2 \\
\hline |456|5|_at & Mm.299073 & 2.931 & 0.0198 & zinc finger protein 358 & Zfp358 \\
\hline |449484_at & Mm.32506 & 2.929 & 0.00956 & stanniocalcin 2 & Stc2 \\
\hline 1436490_x_at & Mm.297440 & 2.888 & 0.0446 & RAN, member RAS oncogene family & Ran \\
\hline 1447786_at & Mm.864I3 & 2.684 & 0.0443 & pleckstrin homology, Sec7 and coiled-coil domains I & Pscdl \\
\hline 1457684_at & Mm.277465 & 2.683 & 0.0331 & heat shock protein I2B & Hspa I 2b \\
\hline |43757|_at & Mm.261602 & 2.572 & 0.023 & hypermethylated in cancer 2 & Hic2 \\
\hline |427637_a_at & Mm.89935 & 2.516 & 0.048 & desmocollin 3 & Dsc3 \\
\hline 1421275_s_at & Mm.35476I & 2.438 & 0.00644 & suppressor of cytokine signaling 7 & Socs7 \\
\hline |44464|_at & Mm.71996 & 2.351 & 0.0412 & adenylate cyclase 3 & Adcy3 \\
\hline 1459828_at & Mm.1963 & 2.326 & 0.00118 & serine/arginine repetitive matrix I & Srrm I \\
\hline 1421660_at & Mm.31453। & 2.323 & 0.026 & sodium channel, voltage-gated, type IX, alpha polypeptide & $\operatorname{Scn} 9 \mathrm{a}$ \\
\hline |4453|4_at & Mm.4866 & 2.302 & 0.000693 & ets variant gene I & Etvl \\
\hline 142|234_at & Mm.332607 & 2.248 & 0.0373 & transcription factor I & Tcfl \\
\hline |442456_at & Mm. 172679 & 2.215 & 0.0262 & spermatogenesis associated 5 & Spata5 \\
\hline |44|483_at & Mm.33608I & 2.153 & 0.0398 & SLIT and NTRK-like family, member 2 & Slitrk2 \\
\hline |438597_x_at & Mm. 196508 & 2.137 & 0.0365 & mortality factor 4 like I & Morf4II \\
\hline 1439428_x_at & Mm.247I43 & 2.118 & 0.0407 & GDP-mannose 4, 6-dehydratase & Gmds \\
\hline |459924_at & Mm.3408I8 & 2.088 & 0.0306 & ATPase, $\mathrm{H}+$ transporting, lysosomal V0 subunit a isoform I & Atp6v0al \\
\hline 1425429_s_at & Mm.354757 & 2.003 & 0.048 & hypoxia inducible factor 3 , alpha subunit & Hif3a \\
\hline 1427040_at & Mm.1314 & 0.499 & 0.0418 & kidney cell line derived transcript I & $\mathrm{Kdtl}$ \\
\hline 1418745_at & Mm. 139817 & 0.498 & 0.0139 & osteomodulin & Omd \\
\hline 1419230_at & Mm.342959 & 0.49 & 0.00148 & keratin complex 1 , acidic, gene 12 & KrtI-I2 \\
\hline 1423170_at & Mm.236009 & 0.487 & 0.000269 & $\begin{array}{l}\text { TAF7 RNA polymerase II, TATA box binding protein (TBP)-associated } \\
\text { factor }\end{array}$ & Taf7 \\
\hline |41923|_s_at & Mm.342959 & 0.487 & 0.00492 & keratin complex 1 , acidic, gene 12 & $\mathrm{KrtI}-12$ \\
\hline 1457306_at & Mm.6988 & 0.483 & 0.0387 & aminolevulinate, delta-, dehydratase & Alad \\
\hline 1432834_at & Mm.24242 & 0.475 & 0.00679 & carboxypeptidase B2 (plasma) & Cpb2 \\
\hline 1449739_at & Mm.28I464 & 0.472 & 0.0126 & phosphatidylserine synthase I & Ptdss I \\
\hline 1460250_at & Mm.43375 & 0.466 & 0.00542 & sclerostin domain containing I & Sostdcl \\
\hline |42529|_at & Mm.4985 & 0.466 & 0.00137 & forkhead box JI & Foxjl \\
\hline | 442344_at & Mm.82680 & 0.465 & 0.00971 & API gamma subunit binding protein I & Aplgbpl \\
\hline |456247_x_at & Mm. 18565 & 0.462 & 0.0237 & LIM domain only 6 & Lmo6 \\
\hline 1450760_a_at & Mm.39999 & 0.462 & 0.0157 & inhibitor of growth family, member 3 & Ing3 \\
\hline 1418082_at & Mm. 10265 & 0.456 & 0.0305 & N-myristoyltransferase I & $\mathrm{Nmtl}$ \\
\hline 1427612_at & Mm. 171224 & 0.444 & 0.00697 & defensin beta 9 & Defb9 \\
\hline 143905I_a_at & Mm.260504 & 0.442 & 0.0497 & MAP/microtubule affinity-regulating kinase 4 & Mark4 \\
\hline 1421906_at & Mm. I2926 & 0.427 & 0.0224 & peroxisome proliferator activated receptor binding protein & Pparbp \\
\hline
\end{tabular}


Table I: Genes at post natal day 10 showing fold change values of $\geq 2$ between $\mathbf{N} \mathrm{I}^{+/-}$and wild type mice (p $\left.\leq 0.05\right)$. (Continued)

\begin{tabular}{|c|c|c|c|c|c|}
\hline 1416203_at & Mm. 18625 & 0.427 & 0.0261 & aquaporin I & Aqpl \\
\hline 1444960_at & Mm.243855 & 0.412 & 0.031 & cytochrome P450, family 2 , subfamily u, polypeptide I & Cyp2ul \\
\hline 1424273_at & Mm.29119 & 0.402 & 0.00623 & cytochrome P450, family 2 , subfamily c, polypeptide 70 & Сур2c70 \\
\hline 1450995_at & Mm.2135 & 0.37 & 0.0443 & folate receptor I (adult) & Folrl \\
\hline 1418554_at & Mm.2857 & 0.366 & 0.0107 & adrenomedullin receptor & Admr \\
\hline |4247|3_at & Mm.28623 & 0.36 & 0.0295 & calmodulin-like 4 & Calml4 \\
\hline |454866_s_at & Mm.44747 & 0.357 & 0.00964 & chloride intracellular channel 6 & Clic6 \\
\hline |449693_at & Mm.258589 & 0.353 & 0.0446 & mitogen activated protein kinase kinase kinase 7 & Map3k7 \\
\hline 1452546_x_at & Mm.221026 & 0.337 & 0.0323 & defensin beta II & DefbII \\
\hline 1419662_at & Mm.4258 & 0.332 & 0.0234 & osteoglycin & Ogn \\
\hline 1417297_at & Mm.328900 & 0.294 & 0.0313 & inositol 1,4,5-triphosphate receptor 3 & Itpr3 \\
\hline |436477_x_at & Mm.240224 & 0.288 & 0.0103 & RAB2, member RAS oncogene family & Rab2 \\
\hline 1459738_x_at & Mm.III4 & 0.286 & 0.0425 & galactosidase, alpha & Gla \\
\hline 1439167_at & Mm.28I738 & 0.284 & 0.0116 & peroxisomal trans-2-enoyl-CoA reductase & Pecr \\
\hline 1420652_at & Mm.21632I & 0.27 & 0.0445 & arginine-tRNA-protein transferase I & Atel \\
\hline 1427560_at & Mm.3410 & 0.259 & 0.0328 & sine oculis-related homeobox 5 homolog (Drosophila) & Six 5 \\
\hline |4352|4_at & Mm.40016 & 0.241 & 0.00726 & gap junction membrane channel protein alpha 12 & Gjal2 \\
\hline 1425794_at & Mm.20993। & 0.236 & 0.0234 & polymerase (DNA directed), alpha 2 & Pola2 \\
\hline$|426| 5 \mid$ _a_at & Mm.272264 & 0.235 & 0.0214 & syntaxin 3 & Stx3 \\
\hline 1439878_at & Mm.207365 & 0.208 & 0.0151 & involucrin & $|v|$ \\
\hline 1450805_at & Mm.338890 & 0.202 & 0.0179 & sarcoglycan, delta (dystrophin-associated glycoprotein) & Sgcd \\
\hline 1438406_at & Mm. 194950 & 0.195 & 0.00559 & scavenger receptor class $F$, member 2 & Scarf2 \\
\hline 1439457_x_at & Mm.9852 & 0.189 & 0.0278 & autophagy I2-like (S. cerevisiae) & Apg 121 \\
\hline 1444680_at & Mm.208970 & 0.171 & 0.0137 & $\begin{array}{l}\text { positive cofactor } 2 \text {, multiprotein complex, glutamine/Q-rich-associated } \\
\text { protein }\end{array}$ & Pcqap \\
\hline |42617|_x_at & Mm. 193478 & 0.17 & 0.0166 & killer cell lectin-like receptor, subfamily A, member 7 & Klra7 \\
\hline 1418618 at & Mm.2657 & 0.0828 & $6.20 \mathrm{E}-05$ & engrailed I & Enl \\
\hline
\end{tabular}

afflicted with NF1 show learning disabilities $(30-65 \%)$ [3]. These children perform poorly on tasks requiring developed spatial memory and visual-spatial functioning. Though the cognitive manifestations of NF1 have been characterized, no substantial link between the genetic and cognitive deficits has been formed. In addition, no link has been shown between specific mutations within the causative gene and the degree of physical and mental impairment.

NF1 is caused by a heterozygous loss of function mutation within the NF1 gene located on chromosome 17q11.2. The NF1 gene encodes a ubiquitously expressed cytoplasmic protein called neurofibromin. The suspected function of neurofibromin is based on sequence homology to known GTPase Activating Proteins (GAPs) as well as through cell biological and functional studies of mutant neurofibromin [4]. Neurofibromin inactivates Ras (RasGTP) by converting it to Ras-GDP. Loss of neurofibromin within a cell would thus result in constitutive activation of the Ras signaling pathway, ultimately resulting in cell growth. Ras signaling has also been implicated in neuronal activity and synaptic plasticity [5].

It has been hypothesized that neurofibromin may also act as a modulator of adenylyl cyclase or may facilitate microtubule binding [5]. Studies in drosophila, cultured murine neurons, and $\mathrm{Nf1} \%$ mouse embryos (E12.5) have shown that neurofibromin is necessary for the activation of adenylyl cyclase by pituitary adenylate cyclase activating peptide (PACAP) [6-9]. Drosophila models deficient for neurofibromin have also been used to determine if the learning deficits seen within mammalian samples are caused by the developmental abnormalities seen in NF1 or if the cognitive defects are due directly to decreased neurofibromin activity. Heat-shock induced neurofibromin was expressed in adult $\mathrm{NF1} \%$ - fruit flies, rescuing the learning deficits, indicating that developmental factors are not causing the cognitive deficits [10]. Heat-shock induced cAMP dependent protein kinase (PKA) expression also rescued the learning deficits in adult $N F 1^{-}$- fruit flies, indicating that the cellular defect must be upstream of PKA within the adenylate cyclase signaling pathway [10]. In this Drosophila model it is hypothesized that neurofibromin acts as a GAP specific to G-proteins, influencing the interaction between G-proteins and adenylate cyclase [10]. The elucidation of auxiliary functions of neurofibromin can be facilitated by further study of such model organisms containing targeted mutations of the Nf1 gene (Drosophila and murine systems).

A mouse model of the cognitive deficits associated with Neurofibromatosis type 1 was first developed in 1994 and has since been utilized in the investigation and characterization of the disease $[11,12]$. The learning deficits seen in the $\mathrm{Nf1}^{+/-}$mice include difficulties in spatial learning and decreased hippocampal long-term potentiation (LTP) [5]. Increased levels of GABA-mediated inhibition have been 
Table 2: Genes at post natal day 15 showing fold change values of $\geq 2$ between $\mathrm{Nfl}^{+/-}$and wild type mice $(\mathrm{p} \leq 0.05)$

\begin{tabular}{|c|c|c|c|c|c|}
\hline Probe Set & Unigene & Fold Change & P Value & Gene Name & Gene Symbol \\
\hline |425754_a_at & Mm. 1420 & 12.45 & 0.0354 & butyrophilin, subfamily I, member AI & Btnlal \\
\hline |4|8555_x_at & Mm.21642 & 6.649 & 0.00469 & Spi-C transcription factor (Spi-I/PU.I related) & Spic \\
\hline 1420992_at & Mm. 10279 & 6.523 & 0.00774 & ankyrin repeat domain I (cardiac muscle) & AnkrdI \\
\hline 1418358_at & Mm.331192 & 6.182 & 0.0229 & mitochondrial capsule selenoprotein & Mcsp \\
\hline 1458958_at & Mm.20904I & 6.01 & 0.00798 & neighbor of Punc EII & Nope \\
\hline |447392_s_at & Mm.276736 & 5.357 & 0.0228 & carboxypeptidase D & Cpd \\
\hline 1450439_at & Mm.248353 & 5.224 & 0.0198 & host cell factor $\mathrm{Cl}$ & $\mathrm{Hcfcl}$ \\
\hline |435410_at & Mm.159608 & 4.96 & 0.0419 & testicular cell adhesion molecule I & Tcam l \\
\hline |454032_at & Mm. 126079 & 4.831 & 0.0386 & neuropilin (NRP) and tolloid (TLL)-like 2 & Neto2 \\
\hline |4384|4_at & Mm.39703 & 4.337 & 0.0381 & fukutin related protein & Fkrp \\
\hline 1420652_at & Mm.21632I & 4.245 & 0.0175 & arginine-tRNA-protein transferase I & Atel \\
\hline 1425069_at & Mm.264252 & 4.15 & 0.00663 & similar to nuclear protein, $25 \mathrm{~K}$ - mouse & LOC223706 \\
\hline 1421515_at & Mm.242728 & 3.998 & 0.0161 & nuclear receptor subfamily 6 , group A, member I & Nr6al \\
\hline |447362_at & Mm.29133 & 3.983 & 0.04 & budding uninhibited by benzimidazoles I homolog, beta & Bublb \\
\hline 1456697_x_at & Mm.22480 & 3.814 & 0.0171 & cyclin $\mathrm{D}$ binding myb-like transcription factor I & Dmtfl \\
\hline 1422260_x_at & Mm. 14302 & 3.75 & 0.0144 & chemokine (C-C motif) receptor 5 & Ccr5 \\
\hline |420253_at & Mm.201322 & 3.638 & 0.0362 & dolichol-phosphate (beta-D) mannosyltransferase I & Dpml \\
\hline 1427825_at & Mm.272223 & 3.568 & 0.0202 & solute carrier organic anion transporter family, member lb2 & Slcolb2 \\
\hline 1458678_at & Mm.347976 & 3.356 & 0.00654 & NADH dehydrogenase (ubiquinone) I, alpha/beta subcomplex, I & Ndufabl \\
\hline 1441659_at & Mm. 151308 & 3.305 & 0.0274 & D4, zinc and double PHD fingers, family 3 & Dpf3 \\
\hline 14|70|5_at & Mm.4I265 & 3.094 & 0.0256 & Ras association (RalGDS/AF-6) domain family 3 & Rassf3 \\
\hline |4|8536_at & Mm.3442I & 3.034 & 0.0147 & histocompatibility $2, \mathrm{Q}$ region locus 7 & $\mathrm{H} 2-\mathrm{Q} 7$ \\
\hline 1437847_x_at & Mm.28275 & 2.999 & 0.0357 & RNA binding motif protein, $X$ chromosome & Rbmx \\
\hline |440837_at & Mm.358604 & 2.771 & 0.031 & histocompatibility 2,0 region beta locus & $\mathrm{H} 2-\mathrm{Ob}$ \\
\hline 14|8595_at & Mm. 12966 & 2.751 & 0.041 & plasma membrane associated protein, S3-12 & S3-12 \\
\hline 1422278_at & Mm.327835 & 2.707 & $0.0047 \mid$ & dopamine receptor 3 & Drd3 \\
\hline 1425398_at & Mm.37I766 & 2.539 & 0.0134 & histone $\mathrm{I}, \mathrm{H} 2 \mathrm{bc}$ & Histlh2bc \\
\hline |425443_at & Mm.244858 & 2.53 & 0.0347 & transcription factor AP-2, delta & Tcfap2d \\
\hline 1419623_at & Mm.86657 & 2.515 & 0.0308 & protease, serine, 21 & Prss21 \\
\hline 1421359_at & Mm.57I99 & 2.51 & 0.000164 & ret proto-oncogene & Ret \\
\hline |450455_s_at & Mm.89993 & 2.504 & 0.00985 & aldo-keto reductase family $\mathrm{I}$, member $\mathrm{Cl} 2$ & Akrlcl2 \\
\hline |4207|0_at & Mm.4869 & 2.422 & 0.0149 & reticuloendotheliosis oncogene & Rel \\
\hline |434885_at & Mm. 155687 & 2.357 & 0.0457 & DNA segment, Chr 7, ERATO Doi 413, expressed & D7Ertd4I3e \\
\hline 145|463_at & Mm.291372 & 2.351 & 0.0344 & Rho GTPase activating protein 8 & Arhgap8 \\
\hline 1416309_at & Mm.2900I5 & 2.299 & 0.00369 & nucleolar and spindle associated protein I & Nusapl \\
\hline |425064_at & Mm.250265 & 2.272 & 0.00144 & aryl hydrocarbon receptor nuclear translocator & Arnt \\
\hline |42572|_at & Mm.221688 & 2.245 & 0.0475 & pleckstrin homology domain interacting protein & Phip \\
\hline |421953_at & Mm.21048 & 2.219 & 0.0017 & v-crk sarcoma virus CTIO oncogene homolog (avian)-like & Crkl \\
\hline 1426520_at & Mm. 104932 & 2.199 & 0.0211 & B-cell translocation gene 4 & Btg4 \\
\hline 1450104_at & Mm.3037 & 2.172 & 0.0339 & a disintegrin and metalloprotease domain 10 & Adam I0 \\
\hline 1436008_at & Mm.37I590 & 2.134 & 0.00836 & tumor protein D52 & Tpd52 \\
\hline 1419535_at & Mm.263706 & 2.121 & 0.0243 & solute carrier organic anion transporter family, member $6 \mathrm{~b} /$ & Slco6bl \\
\hline |420499_at & Mm.1065I & 2.121 & 0.0318 & GTP cyclohydrolase I & Gch \\
\hline 1451870_a_at & Mm.253518 & 2.011 & 0.0256 & bromodomain containing 4 & Brd4 \\
\hline 1445886_at & Mm.4454 & 0.497 & 0.0367 & ELK3, member of ETS oncogene family & Elk3 \\
\hline 1425690_at & Mm.218788 & 0.461 & 0.0463 & beta-I,3-glucuronyltransferase I (glucuronosyltransferase P) & B3gat I \\
\hline 1441966_at & Mm. 124567 & 0.452 & 0.0279 & transient receptor potential cation channel, subfamily $M$, member 3 & Trpm3 \\
\hline 1427635_at & Mm.30355 & 0.438 & 0.0348 & kinesin family member $5 \mathrm{~A}$ & Kif5a \\
\hline 1418194_at & Mm.271670 & 0.421 & 0.0445 & $\begin{array}{l}\text { UDP-N-acetyl-alpha-D-galactosamine:polypeptide N- } \\
\text { acetylgalactosaminyltransferase } 10\end{array}$ & Galnt 10 \\
\hline 1416239_at & Mm.3217 & 0.42 & 0.00011 & argininosuccinate synthetase I & Assl \\
\hline 1449266_at & Mm. $13 \mid 408$ & 0.415 & 0.0128 & methyl CpG binding protein 2 & Mecp2 \\
\hline 1440072_at & Mm.210787 & 0.407 & 0.021 & glucocorticoid induced transcript I & Glccil \\
\hline 1430357_at & Mm.37I563 & 0.398 & 0.0139 & H3 histone, family 3B & $\mathrm{H} 3 \mathrm{f} 3 \mathrm{~b}$ \\
\hline 1425707_a_at & Mm.328720 & 0.387 & 0.0192 & potassium inwardly-rectifying channel, subfamily J, member 6 & Kcnj6 \\
\hline |446|85_at & Mm.2II58 & 0.353 & 0.0479 & FK506 binding protein 12-rapamycin associated protein I & Frapl \\
\hline 1422|44_at & Mm.3510 & 0.328 & 0.0259 & inhibin beta $\mathrm{E}$ & Inhbe \\
\hline |42|447_at & Mm.303355 & 0.298 & 0.000377 & one cut domain, family member I & Onecut I \\
\hline |449907_at & Mm. 174I33 & 0.255 & 0.0278 & beta-carotene 15, 15'-dioxygenase I & Bcdol \\
\hline
\end{tabular}


Table 2: Genes at post natal day 15 showing fold change values of $\geq 2$ between $\mathbf{N f I}{ }^{+/}$and wild type mice (p $\left.\leq 0.05\right)$ (Continued)

\begin{tabular}{|c|c|c|c|c|c|}
\hline |421073_a_at & Mm. 18509 & 0.237 & 0.0359 & prostaglandin E receptor 4 (subtype EP4) & Ptger4 \\
\hline |420296_at & Mm.254370 & 0.232 & 0.00578 & chloride channel 5 & Clen5 \\
\hline 1418|58_at & Mm.20894 & 0.205 & 0.0342 & transformation related protein 63 & Trp63 \\
\hline |448074_at & Mm.5033 & 0.174 & 0.0361 & relaxin I & Rln I \\
\hline 1453630_at & Mm.27I953 & 0.122 & 0.0047 I & $\begin{array}{l}\text { UDP-N-acetyl-alpha-D-galactosamine:polypeptide N- } \\
\text { acetylgalactosaminyltransferase } 14\end{array}$ & Galnt 14 \\
\hline |446|62_at & Mm. I 25979 & 0.0938 & 0.0101 & poly A binding protein, cytoplasmic 5 & Pabpc5 \\
\hline
\end{tabular}

linked to these cognitive deficits within the mouse model and introduction of a $\mathrm{GABA}_{\mathrm{A}}$ receptor antagonist (Picrotoxin) into the knockout mouse system restores normal LTP in the hippocampus [5]. Double knockout mice heterozygous for mutations in both the Nf1 and K-ras genes $\left(\mathrm{Nf1} 1^{+/} / \mathrm{K}_{-} \mathrm{ras}^{+/}\right)$show similar performance on the hidden water maze task as wildtype mice [5]. Inactivating mutations within the $K$-ras gene decrease the level of functional Ras protein within the cells. Observations that the combination of $N f 1$ and $K$-ras mutations in mice results in normal cognitive function support the link between an increase in Ras activity and visual-spatial learning deficits. Ras activity within cells can also be modulated through the introduction of farnesyl-transferase inhibitors. By blocking the post-translational farnesylation of Ras protein in the $\mathrm{Nf1+/-}$ mutant mice, performance on visual-spatial tasks are comparable to wildtype mice, rescuing the phenotype

$[5]$.

The detailed mechanism by which diminished function of neurofibromin protein leads to defects in hippocampal long term potentiation, and subsequent deficits in cognition and learning is not fully understood. Some of the intermediate steps are dependent on gene transcription and new protein synthesis [13]. It is thus appropriate to study the cumulative effect of Nf1 gene mutation in the developing hippocampus, and characterize alterations in gene expression profiles in this model system. Here we describe the results of our studies comparing gene expression profiles in the hippocampi of $\mathrm{Nf}^{+/-}$and wild type mice at postnatal ages 10, 15, and 20 days, a time period that is critical for syanptogenesis and synaptic remodeling in the hippocampus. Application of new high-resolution genomic technologies to the Nf1 knock-out mouse model may provide new insight into the mechanisms behind the cognitive impairment in humans with Neurofibromatosis type 1.

\section{Results}

Genes showing fold change values of $\geq 2.0$ and corresponding p-values of $\leq 0.05$ were visualized across the time series (post natal days 10, 15, and 20) (Fig. 1). Figure 1 shows the expression profiles of genes across the time series and includes only genes which are significantly changed at a minimum of one time point. Individual lists of genes significantly changed at each individual time point are contained in Tables 1, 2, and 3. Four genes were dysregulated at more than one time point: Ate1, Tcfap $2 \mathrm{~d}$, Rad5111, Arhgap8. The lists of dysregulated genes include a myriad of genes including enzymes, receptors, channel molecules, and transcription factors. All raw expression data is publicly available $[14,15]$.

RT-PCR validation was performed on a select group of genes showing significantly $(\mathrm{p} \leq 0.05)$ regulated fold changes of $\geq 2$ fold. As can be seen in Table 4, Affymetrix microarray fold change values correlate well with the trend of transcript levels calculated through RT-PCR reactions. Though the exact fold change values are not identical, the two assays show consistent trends of regulation.

Genes significantly dysregulated at post natal days 10, 15, and 20 were entered into the GeneGo network developing program, along with proteins known to be involved in learning and memory (Tab, ErbB-2, CREB, calcium, AMPA, SH2, ShcC, NMDA receptor, TrkB, MAPK, CaM Kinase II, calcineurin, Rho-associated kinase, MAP2, peripherin, ERK1, ERK2, TARP, PAK3) [16]. A functional network was created identifying genes within the data set that are linked to these known mediators of long term potentiation (LTP).

As expected, the GeneGo networking software identified direct modulation of Ras activity (here notated H-Ras) by neurofibromin. The networking program also identified neurofibromin as a physical binding partner with both the kinesin heavy chain and amyloid beta precursor protein (APP) (Fig. 2). While no significant dysregulation of APP was seen in the data set, members of the kinesin motor protein family were downregulated in the $\mathrm{Nf1+-}$ mice at post natal days 15 and 20 (Tables 2 and 3).

Gene expression analysis shows a 2.7 fold increase in the expression of dopamine 3 receptor in $\mathrm{Nf1+/}$-brains at post natal day 15 . The GeneGo network development software highlights binding properties between this dopamine receptor and filamin A, a protein involved in cytoskeleton organization through binding with integrins, receptors, and second messengers [17]. The associations between integrins and filamin A and between integrins and APP seen in the GeneGo network links neurofibromin to the dopamine receptor. Here it is hypothesized that the APP 
Table 3: Genes at post natal day 20 showing fold change values of $\geq 2$ between $\mathrm{Nfl}^{+/-}$and wild type mice $(\mathrm{p} \leq 0.05)$

\begin{tabular}{|c|c|c|c|c|c|}
\hline Probe Set & Unigene & Fold Change & P Value & Gene Name & Gene Symbol \\
\hline 1425947_at & Mm.240327 & 13.26 & 0.000122 & interferon gamma & Ifng \\
\hline 1442827_at & Mm.38049 & 4.568 & 0.0446 & toll-like receptor 4 & Tlr4 \\
\hline 1425478_x_at & Mm.240044 & 4.347 & 0.0178 & ubiquitin-conjugating enzyme E2I & Ube2i \\
\hline 1450337_a_at & Mm.23788 & 3.618 & 0.0132 & NIMA (never in mitosis gene a)-related expressed kinase 8 & Nek8 \\
\hline |4224||Is_at & Mm.327088 & 3.478 & 0.0376 & ribonuclease, RNase A family 3 & Rnase3 \\
\hline 1422297_at & Mm.I58264 & 2.727 & 0.0381 & prefoldin 5 & Pfdn5 \\
\hline |438564_at & Mm.207360 & 2.573 & 0.0405 & growth arrest specific 2 & Gas2 \\
\hline 1433732_x_at & Mm.281018 & 2.313 & 0.0229 & insulin-like growth factor 2, binding protein 3 & $\lg 2 \mathrm{bp} 3$ \\
\hline 14278|6_at & Mm.2I84I & 2.306 & 0.0137 & splicing factor, arginine/serine-rich 2 (SC-35) & Sfrs2 \\
\hline 1452349_x_at & Mm.2554I4 & 2.149 & 0.0043 & interferon activated gene 205 & Ifi205 \\
\hline 1418604_at & Mm.435I & 2.038 & 0.0134 & arginine vasopressin receptor IA & Avprla \\
\hline 1438156_x_at & Mm. 18522 & 0.496 & 0.0254 & carnitine palmitoyltransferase la, liver & Cptla \\
\hline |4267|4_at & Mm. 131618 & 0.488 & 0.00577 & DNA segment, Chr II, ERATO Doi 18 & DIIErtdI8e \\
\hline |455332_x_at & Mm.33016I & 0.48 & 0.00869 & Fc receptor, lgG, low affinity Ilb & Fcgr2b \\
\hline |45095|_at & Mm.14910 & 0.478 & 0.0373 & chondroitin sulfate proteoglycan 6 & Cspg6 \\
\hline 1423719_at & Mm.3783 & 0.359 & 0.0127 & cDNA sequence U46068 & U46068 \\
\hline 1419109_at & Mm.39968 & 0.357 & 0.0432 & histidine rich calcium binding protein & Hrc \\
\hline |460746_at & Mm.236II4 & 0.356 & 0.0339 & fidgetin-like I & Fignll \\
\hline 1433382_at & Mm.79/27 & 0.352 & 0.0427 & dynein, axonemal, intermediate chain I & Dnaicl \\
\hline 1449207_a_at & Mm.258846 & 0.297 & 0.0232 & kinesin family member $20 \mathrm{~A}$ & Kif20a \\
\hline |455990_at & Mm.259374 & 0.279 & 0.00332 & kinesin family member 23 & Kif23 \\
\hline 1436682_at & Mm.3532 & 0.273 & 0.0428 & thymosin, beta 10 & Tmsblo \\
\hline 1430486_at & Mm.34I756 & 0.232 & 0.0143 & RAD5I-like I (S. cerevisiae) & $\operatorname{Rad5}$ III \\
\hline 1426598_at & Mm.20477 & 0.222 & 0.0128 & ubiquitously transcribed tetratricopeptide repeat gene, $Y$ chromosome & Uty \\
\hline 145|463_at & Mm.291372 & 0.193 & 0.0173 & Rho GTPase activating protein 8 & Arhgap8 \\
\hline |44|429_at & Mm.26I59| & 0.188 & 0.036 & insulin receptor substrate 4 & Irs4 \\
\hline 1452563_a_at & Mm.262676 & 0.109 & 0.00609 & selected mouse cDNA on the $Y$ & Smcy \\
\hline 1457582_at & Mm.20477 & 0.0739 & 0.0209 & ubiquitously transcribed tetratricopeptide repeat gene, $Y$ chromosome & Uty \\
\hline 1426438_at & Mm.302938 & 0.0533 & 0.0444 & DEAD (Asp-Glu-Ala-Asp) box polypeptide 3, Y-linked & Ddx3y \\
\hline
\end{tabular}

and integrin proteins are essential for the transport of the dopamine receptor protein down the axon via the filamin proteins. Several other genes linked to intracellular structure and protein trafficking were also dysregulated in the dataset. Aberrant movement of these complexes within the neurons could lead to abnormal localization or abundance of receptors in neuronal processes.

\section{Discussion}

Learning and memory deficits observed in human Neurofibromatosis type 1 patients have been modeled in a Nf1 gene knock-out murine system showing well characterized spatial learning and memory deficiencies. These mutant mice exhibit increased levels of activated Ras (RasGTP) and increased GABA mediated inhibition. Research has shown that the cognitive deficit in this mouse model can be rescued by inactivating Ras (through genetic modification or pharmacological treatment) or by blocking postsynaptic GABA uptake [5].

We used gene expression profiling to investigate the genetic pathways leading to GABA mediated inhibition, and to link deficiency of neurofibromin to long term changes at the synapse. Differentially regulated genes at postnatal days 10, 15, and 20 were analyzed using GeneGo networking software. This network analysis identified direct interactions between NF1, APP, integrins, filamins, and kinesins. Though compound binding properties were identified in silico, these interactions must be investigated within the cells including how these interactions affect the activity of each protein or the localization of the proteins with the cell. It is known that kinesin proteins act within the nerve cell to carry proteins and cellular organelles from the cell body down neuronal processes [18]. Interaction between neurofibromin and kinesins suggests a mechanism for intracellular localization of the neurofibromin/APP complex. Current literature has identified physical interactions between NF1, $\mathrm{APP}$, and kinesin- 1 integral to vesicle transport in melanocytes and neurons. This study proposed that NF1 gene mutations impair vesicle trafficking through aberrant kinesin transport of both NF1 and APP [19].

Through network analysis an interaction between APP and the dopamine 3 receptor (DRD3) was idenified. DRD3, a member of the G alpha inhibitory G protein coupled receptor family, was also dysregulated in the mutant mice, showing a 3 fold increase in expression in the hip- 
Table 4: Affymetrix and RT-PCR fold change values for genes significantly regulated in the hippocampus of $\mathrm{NfI}^{+/-}$mice

\begin{tabular}{lllrrrr}
\hline Gene Symbol & Gene Name & Probe ID & Fold Change & P-value & $\begin{array}{l}\text { RT-PCR Fold } \\
\text { Change }\end{array}$ & RT-PCR P-value \\
& & & & & \\
\hline Stcl & stanniocalcin I & 1421984_at & 12.2 & 0.0021 & 1.7592 & 0.0100 \\
Htr5a & 5-hydroxytryptamine (serotonin) receptor 5A & 1422207_at & 9.391 & 0.0006 & 2.0005 & 0.0580 \\
Neto2 & neuropilin (NRP) and tolloid (TLL)-like 2 & 1454032_at & 4.831 & 0.0386 & 1.4045 & 0.0415 \\
Frapl & FK506 binding protein 2-rapamycin associated & 1446185_at & 0.353 & 0.0479 & 0.3927 & $0.47 \mid 11$ \\
& protein I & & & & &
\end{tabular}

pocampus. The DRD3 receptor is a member of the D2 like dopamine receptor superfamily which selectively mediates inhibition of adenylate cyclase $\mathrm{V}$ [20]. The DRD3 receptor expression has been localized to limbic areas of the brain, where it acts via the $G_{0}$ subunit and adenylate cyclase to decrease cAMP levels [20,21]. It is unknown if alterations in expression of these receptors are involved in either GABA mediated inhibition, or in other pathways leading to the phenotypic leaning and memory deficits characteristic of NF1.

The results of our network analysis are shown in Figure 2, implying a functional connection between neurofibromin and the amyloid beta precursor protein/integrin/filamin complex, which is in turn related to the dopamine receptors (Drd3). These potential interactions between neurofibromin and APP or DRD3 might lead to new ideas about how neurofibromin is involved in cellular signaling and synaptic plasticity. Future research should include studies of APP and related signaling pathways as well as dopaminergic systems in NF1 models. This also raises the possibility of investigating these pathways in human patients using modern imaging modalities (such as positron emission tomography).

\section{Methods}

Animals (breeding, dissection, genotyping, and sexing) $\mathrm{Nf1^{+/ }}$ mice were purchased from Jackson Laboratory (symbol Nf1 ${ }^{\mathrm{tm} 1 F \mathrm{Fr}}$ ) [22]. Breeder pairs were allowed to mate, and offspring were collected at postnatal days 10 , 15 , and 20. At these ages, mice were euthanized and bilateral brain regions (hippocampus, cerebral cortex, cerebellum, olfactory bulb, and basal ganglion/thalamus) dissected and immediately flash frozen in an ethanol/dry ice bath. Liver and blood were also collected from each mouse. All tissues were stored at $-80^{\circ} \mathrm{C}$ until RNA or DNA extraction was performed.

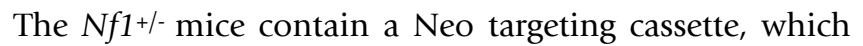
disrupts the Nf1 gene to form the knockout allele and can be tested using primers specific for this insert. Genotyping was performed through a series of PCR reactions containing one microliter (approximately $100 \mathrm{ng}$ ) of sample DNA, $10 \mathrm{pM}$ of primers, $1 \times$ PCR buffer, $2.25 \mathrm{mM} \mathrm{MgCl}_{2}$, $10 \mathrm{mM}$ of each dNTP, and 1 unit of Taq Gold polymerase.
The PCR cycling program started with $95^{\circ} \mathrm{C}$ for 5 minutes followed by 35 cycles of $94^{\circ} \mathrm{C}$ for 1 minute, $55^{\circ} \mathrm{C}$ for 1 minute, and $72^{\circ} \mathrm{C}$ for 1 minute. The final step was $72^{\circ} \mathrm{C}$ for 10 minutes followed by a $4^{\circ} \mathrm{C}$ hold. Genotyping and sexing primers included:

Control primers (1.2 kilobase product):

mMeC.U256 Forward 5'-GTATGATGACCCCACCTTGC

mMeC.L1452 Reverse 5'-TTCAGTCCCTTCCCGCTTTT

Neo specific primers (2 kilobase product):

Neo5' Forward 5'-GCGTGTTCGAATTCGCCAATG

Exon 32 Reverse 5'-GAAGGACAGCATCAGCATG

Y Chromosome specific primers (200 base pair product):

\section{STS162400 Forward 5'GCAAACAACCTCATAGTCCC}

STS162400 Reverse 5'CTGGATTTGTGACAAGGAGC

The reaction product was visualized by $2 \%$ agarose gel electrophoresis and the presence of bands noted. The control PCR reaction detected a segment of the MeCP2 gene on the X chromosome, and was used to monitor the integrity of template genomic DNA, and the amplification reaction. The presence of a single $2 \mathrm{~kb}$ band in the Neo specific reaction indicated a $\mathrm{Nf1+/}$ - heterozygous mouse, whereas wild type genomic DNA was represented by absence of a band. Sex was determined by PCR amplification using the Y-chromosome specific primer set. The presence of a band at $200 \mathrm{bp}$ indicates a male mouse and females are shown as the absence of any product.

\section{Affymetrix expression profiling}

Four $\mathrm{Nf1+/}$ mice and four age and sex matched wild type mice were analyzed at each time point. Hippocampi ( 20 mg each) from two mice within a single condition were pooled and divided to yield two identical samples, and each was individually extracted, labeled, and hybridized to the Affymetrix (Murine 430 2.0) chip. Total RNA was isolated from each $40 \mathrm{mg}$ tissue sample using Stratagene 


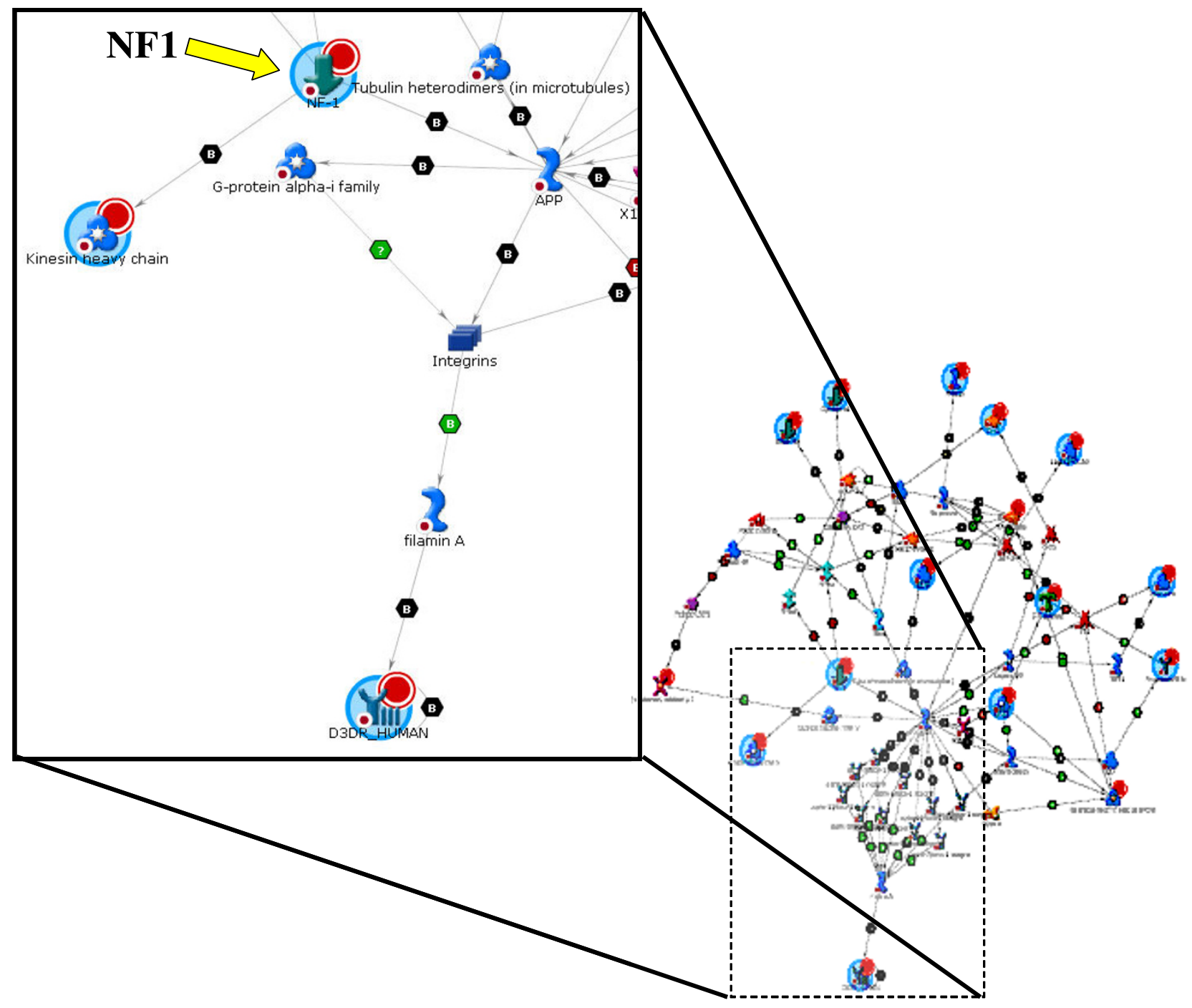

Figure 2

Clustering network connecting neurofibromin primary gene mutation with downstream cellular factors.

Enlargement of signaling network connecting neurofibromin (Nf-I) with the dopamine 3 receptor (D3DR HUMAN) created through the GeneGo networking software. Neurofibromin is indicated as a binding partner for both the kinesin heavy chain and amyliod beta precursor protein (APP). APP binds through integrins to filamin A, a cytoskeletal organizational protein which in turn can bind to and possibly transport the dopamine 3 receptor.

RTPCR Mini-prep kit (the average yield was $15 \mu \mathrm{g}$ RNA/40 mg tissue). Extracted RNA was subsequently cleaned using the Qiagen Mini kit protocol, and the purified RNA was analyzed through agarose gel electrophoresis to insure quality.

cDNA was synthesis from $7 \mu \mathrm{g}$ of purified total RNA, in vitro transcription, and hybridization proceeded as previously described [21]. Strict quality controls require that each RNA sample show $>4 \times$ amplification through the in vitro transcription protocol, that each scanned array should contain $>30 \%$ present calls across the array, and that the $31 / 5$ ' should show consistent values $>3$ indicating low nonspecific hybridization. Arrays that do not satisfy these conditions were not included in the analysis and a second sample of cRNA was created utilizing a second allotment of stored total RNA from the sample. 


\section{Data analysis}

Data was extracted from the array images using Affymetrix Microarray Suite version 5.1 software (MAS5.0). Raw expression data was corrected for saturation at individual probes using an in-house Array Data Manipulation program which replaces S2 values with S1 values if the S2 values are greater than 1500 (baseline normalization of 150) or the S2/S1 signal ratio is less than 0.8 .

The modified gene expression data for each individual array was imported into GeneSpring v 5.0 (Agilent Technologies). For each time point, average fold changes (relative to wildtype expression data) were calculated with error bars. Genes showing expression changes with significant $p$-values $(p \leq 0.05)$ and fold change values of $\geq 2.0$ within at least one time point were exported for functional annotation. Thereafter, the function of each gene was determined through literature searches, genes were binned into ontologic categories, and relevant biological processes and pathways identified.

\section{Modeling the dysfunctional genetic network}

The main goal of both temporal and functional clustering is to generate an integrated pathway beginning with the known primary genetic defect and ending with proteins known to be involved in causing the cognitive pathology under study. This pathway then becomes the template for later in vivo validation. The GeneGo network building algorithms (GeneGo, Inc) were used in an iterative fashion to build gene/protein interaction pathways between known NF1 pathway members (NF1, Ras, GABA) and proteins known to be involved in LTP. The gene expression changes with $\geq 2$ fold differences at $\mathrm{p} \leq 0.05$ were used to seed the algorithms and identified new pathway members which link the primary defect to the cognitive phenotype. All raw expression data is publicly available [14,15].

\section{Validation of the pathogenic cascade}

Quantitative Real-Time PCR - Total RNA was extracted from $\sim 20 \mathrm{mg}$ of hippocampus from $3 \mathrm{Nf1}+/$ - and 3 wild type mice using the Absolutely RNA Miniprep Kit (Stratagene). Reverse transcription reactions were done using 3 $\mu \mathrm{g}$ of total RNA from hippocampus, oligo dT primers, and the Super Script III First Strand cDNA synthesis kit (Invitrogen). Resulting cDNA was amplified on the Chromo4 Four-Color Real-Time System (MJ Research) using the DyNAmo HS SYBR Green qPCR Kit (Finnzymes) and gene specific primers. Standardized and optimized primers were ordered from SuperArray Bioscience Corporation. These included primers designed for Stc1 (stanniocalcin1), Htr5a (5-hydroxytryptamine (serotonin) receptor 5A), Neto2 (neuropilin and tolloid like protein 2), and Frap1 (FK506 binding protein 12-rapamycin associated protein 1 ). The housekeeping gene GAPD (glyceraldehydes-3-phosphate dehydrogenase) was ana- lyzed using the primer set (f-CCAGTATGACTCCACTCACG, r-GAGATGATGACCCGTTTGGC). For amplification, the following program was employed: a $95^{\circ} \mathrm{C}$ heat activation step for $15 \mathrm{~min}$, followed by 40 cycles of $94^{\circ} \mathrm{C}$ for $10 \mathrm{sec}, 55^{\circ} \mathrm{C}$ for $25 \mathrm{sec}, 72^{\circ} \mathrm{C}$ for $30 \mathrm{sec}$, incubate at $72^{\circ} \mathrm{C}$, and plate reads at both $77^{\circ} \mathrm{C}$ and $81^{\circ} \mathrm{C}$. A melting curve was created evaluating the products between $60-95^{\circ} \mathrm{C}$ reading every $0.2^{\circ} \mathrm{C}$.

Primer set specificity was verified through melting curve analysis. The threshold for amplification was set as the number of cycles necessary to reach logarithmic fluorescence accumulation $(\mathrm{C}(\mathrm{T}))$. Fold difference in cDNA concentration was calculated using the formula $F=2((M H-M G)$ (WH-WG)) where $\mathrm{F}=$ fold difference, $\mathrm{MH}=$ mutant housekeeping gene $(\mathrm{GAPD}) \mathrm{C}(\mathrm{T}), \mathrm{MG}=$ mutant gene of interest $\mathrm{C}(\mathrm{T}), \mathrm{WH}=$ wild type housekeeping gene (GAPD) $\mathrm{C}(\mathrm{T})$, $\mathrm{WG}=$ wild type gene of interest C(T) [24,25]. Statistical significance of the resulting fold change values was calculated with a two-tailed t-test assuming unequal variance.

\section{Authors' contributions}

EAD performed all animal breeding and dissection, as well as network analysis and RT-PCR validation. RH performed all Affymetrix expression profiling. DAS developed experimental design and participated in network and data analysis. VN conceived of the study and assisted in data analysis and interpretation of results. All authors read and approved the final manuscript.

\section{Acknowledgements}

This research was supported in part by research grants to DAS from the Department of Defense (CDMRP grant no. DAMD I7-02-I-0642), the NIH Neuroscience Blueprint (U24NS05 1872), and the State of Arizona. VN is supported by funds from the Barrow Neurological Foundation.

\section{References}

I. Rutkowski JL, Wu K, Gutmann DH, Boyer PJ, Legius E: Genetic and cellular defects contributing to benign tumor formation in neurofibromatosis type I. Hum Mol Genet 2000, 9:1059-1066.

2. North K: Neurofibromatosis type I. Am J Med Genet 2000, 97:119-27.

3. Ozonoff S: Cognitive impairment in neurofibromatosis type $I$. Am J Med Genet 1999, 89:45-52.

4. Feldkamp MM, Angelov L, Guha A: Neurofibromatosis type I peripheral nerve tumors: aberrant activation of the Ras pathway. Surg Neurol 1999, 5 I:2 I I-2 I8.

5. Costa RM, Federov NB, Kogan JH, Murphy GG, Stern J, Ohno M, Kucherlapati R, Jacks T, Silva AJ: Mechanism for the learning deficits in a mouse model of neurofibromatosis type I. Nature 2002, 41 5:526-530.

6. Guo HF, The I, Hannan F, Bernards A, Zhong Y: Requirement of Drosophila NFI for activation of adenylyl cyclase by PACAP38-like neuropeptides. Science 1997, 276:795-798.

7. Tong J, Hannan F, Zhu Y, Bernards A, Zhong Y: Neurofibromin regulates $\mathbf{G}$ protein-stimulated adenylyl cyclase activity. Nat Neurosci 2002, 5:95-96.

8. Dasgupta B, Dugan LL, Gutmann DH: The neurofibromatosis I gene product neurofibromin regulates pituitary adenylate cyclase-activating polypeptide-mediated signaling in astrocytes. J of Neurosci 2003, 23:8949-8954. 
9. The I, Hannigan GE, Cowley GS, Reginald S, Zhong Y, Gusella JF, Hariharan IK, Bernards A: Rescue of a Drosophila NFI mutant phenotype by Protein Kinase A. Science 1997, 276:79I-794.

10. Guo HF, Tong J, Hannan F, Luo L, Zhong Y: A neurofibromatosisI-regulated pathway is required for learning in Drosophila. Nature 2000, 403:895-898.

II. Jacks T, Shih TS, Schmitt EM, Bronson RT, Bernards A, Weinberg RA Tumour predisposition in mice heterozygous for a targeted mutation in Nfi. Nat Genet 1994, 7:353-6I.

12. Cichowski K, Shih TS, Jacks T: NfI gene targeting: toward models and mechanisms. Sem in Can Bio 1996, 7:291-298.

13. Martin KC, barad M, Kandel ER: Local protein synthesis and is role in synaose-specific plasticity. Curr OpinNeurobiol 2000, 10:587-592.

14. Translational Genomics Research Institute [http:// www.tgen.org/neurogenomic/data]

15. NIH Neuroscience Microarray Consortium [http://arraycon sortium.tgen.org]

16. Johnston MV, Alemi L, Harum KH: Learning, memory, and transcription factors. Ped Res 2003, 53:369-374.

17. Ueda $\mathrm{K}$, Ohta $\mathrm{Y}$, Hosoya $\mathrm{H}$ : The carboxy-terminal pleckstrin homology domain of ROCK interacts with filamin-A. Biochem Biophys Res Commun 2003, 301:886-90.

18. Brady ST: A novel brain ATPase with properties expected for the fast axonal transport motor. Nature 1985, 3 17:73-75.

19. De Schepper S, Boucneau JM, Westbroek W, Mommaas M, Onderwater J, Messiaen L, Naeyaert JM, Lambert JL: Neurofibromatosis Type I Protein and Amyloid Precursor Protein Interact in Normal Human Melanocytes and Colocalize with Melanosomes. J Invest Dermatol 2006. [Epub ahead of print]

20. Robinson SW, Caron MG: Selective inhibition of adenylate cyclase type $\mathbf{V}$ by the dopamine D3 receptor. Mol Pharmaco 1997, 52:508-5।4.

21. Zaworski PG, Alberts GL, Pregenzer JF, Im WB, Slightom JL, Gill GS: Efficient functional coupling of the human $D 3$ dopamine receptor to $\mathbf{G}_{\mathrm{o}}$ subtype of $\mathbf{G}$ proteins in SH-SY5Y cells. Brt J of Pharmac 1999, I 28: I| $81-1 \mid 88$.

22. Jackson Laboratory [http://www.jax.org]

23. Mintz MB, Sowers R, Brown KM, Hilmer SC, Mazza B, Huvos AG Meyers PA, Lafleur B, McDonough WS, Henry MM, Ramsey KE, Antonescu CR, Chen W, Healey JH, Daluski A, Berens ME, Macdonald TJ, Gorlick R, Stephan DA: An expression signature classifies chemotherapy-resistant pediatric osteosarcoma. Cancer Res 2005, 65(5): 1748-54.

24. Mariani L, McDonough WS, Hoelzinger DB, Beaudry C, Kaczmarek E Coons SW, Giese A, Moghaddam M, Seiler RW, Berens ME: Identification and validation of $\mathrm{P} 3 \mathrm{I} I$ as a glioblastoma invasion gene using laser capture microdissection. Cancer Res 2001 , 61:4190-4196.

25. Lehmann U, Gloeckner S, Kleeberger W, von Wasielevsky HFR, Kreipe $\mathrm{H}$ : Detection of gene amplification in archival breast cancer specimens by laser-assisted microdissection and quantitative real-time polymerase chain reaction. Am Pathol 2000, 156:1855-1864.
Publish with Biomed Central and every scientist can read your work free of charge

"BioMed Central will be the most significant development for disseminating the results of biomedical research in our lifetime. "

Sir Paul Nurse, Cancer Research UK

Your research papers will be:

- available free of charge to the entire biomedical community

- peer reviewed and published immediately upon acceptance

- cited in PubMed and archived on PubMed Central

- yours - you keep the copyright
BiolMedcentral 